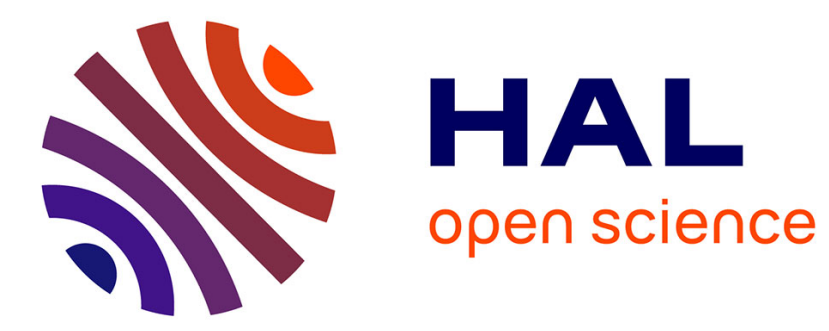

\title{
Toward a Single Reed Mouthpiece for the Oboe
} Sandra Carral, Christophe Vergez, Cornelis Nederveen

\section{To cite this version:}

Sandra Carral, Christophe Vergez, Cornelis Nederveen. Toward a Single Reed Mouthpiece for the Oboe. Archives of Acoustics, 2011, 36 (2), pp.1-16. 10.2478/v10168-011-0021-0 . hal-01342859

\section{HAL Id: hal-01342859 \\ https://hal.science/hal-01342859}

Submitted on 26 Jul 2016

HAL is a multi-disciplinary open access archive for the deposit and dissemination of scientific research documents, whether they are published or not. The documents may come from teaching and research institutions in France or abroad, or from public or private research centers.
L'archive ouverte pluridisciplinaire HAL, est destinée au dépôt et à la diffusion de documents scientifiques de niveau recherche, publiés ou non, émanant des établissements d'enseignement et de recherche français ou étrangers, des laboratoires publics ou privés. 


\title{
Toward a Single Reed Mouthpiece for the Oboe ${ }^{(*)}$
}

\author{
Sandra CARRAL ${ }^{(1)}$, Christophe VERGEZ ${ }^{(2)}$, Cornelis J. NEDERVEEN ${ }^{(3)}$ \\ (1) Universität für Musik und darstellende Kunst, Wien \\ Institut für Wiener Klangstil \\ Anton von Webern Platz 1, 1030 Vienna, Austria \\ e-mail: carral@mdw.ac.at \\ ${ }^{(2)}$ Laboratoire de Mécanique et d'Acoustique \\ LMA-CNRS UPR 7051 \\ 31 chemin Joseph-Aiguier \\ 13402 Marseille cedex 20, France \\ e-mail: vergez@lma.cnrs-mrs.fr \\ ${ }^{(3)}$ Acacialaan 20 \\ 2461 AC Pijnacker, The Netherlands \\ e-mail: cjnederv@xs4all.nl \\ (received January 11, 2011; accepted March 15, 2011)
}

Reed woodwind instruments differ in both their geometry (mainly cylindrical or mainly conical) and their excitation mechanism (single or double reed). How much of the resulting sound is due to the single/double reed, and how much to the geometry of the instrument? Measurements done by Almeida et al. (J. Acoust. Soc. Am., 121, 1, 536-546, 2007) show that the flow vs pressure characteristic curve of an oboe reed is not that different from that of a clarinet reed, the only difference probably being due to pressure recovery inside the conical staple. Is it possible to make a single reed mouthpiece for an oboe, while keeping the conical staple, that would still give the oboe its characteristic sound? To find it out, a mouthpiece with the following characteristics was made: A standard clarinet $B^{b}$ reed can be attached to it, its volume is approximately that of the missing part of the instrument cone, and a standard French oboe staple can be inserted to it, so that it can be inserted in the usual way in any french oboe. In this paper, the first prototype of the mouthpiece is shown. Also, a sound comparison of the oboe sounds played with this mouthpiece and a standard double reed by a professional player is presented.

Keywords: single reed, mouthpiece, oboe, double reed, woodwind instruments.

${ }^{(*)}$ A more compact version of this article was originally presented at Vienna Talk 2010 (CARral et al., 2010) and was chosen for journal publication. 


\section{Introduction}

In the family of reed woodwind instruments, all combinations of single/double reed and cylindrical/conical bore exist. Table 1 shows some examples of modern instruments classified according to their excitation mechanism and the geometry of the bore. All the instruments shown in Table 1 have their own particular sound colour, and it is generally easy to distinguish their sounds, provided that the listener is familiar with them. The geometry of both mouthpiece and bore varies greatly between instruments. Moreover, mouthpieces have been designed to be played with particular instruments according to their individual bore shapes and sizes, and not with other instruments, even in the same family. The question: "How would a double reed instrument sound if played with a single reed?" (or vice versa) cannot simply be answered by taking any single reed mouthpiece and attaching it to the instrument, even if this were possible. Rather, one must design a mouthpiece that matches the size and geometry of the instrument in question.

Table 1. Reed and bore configurations of several modern reed woodwind instruments.

\begin{tabular}{|l|c|c|}
\hline & \multicolumn{2}{|c|}{ Reed } \\
\hline Bore & Single & Double \\
\hline Conical & Saxophone & Bassoon \\
& Tárogató & Oboe \\
\hline Cylindrical & Clarinet & Small bagpipe chanters \\
\hline
\end{tabular}

Attaching a single reed to a double reed instrument is not a new idea. In fact, the Edinburgh University Collection of Historic Musical Instruments owns a couple of examples of single reed mouthpieces for oboes and bassoons, that were likely made between the late IX century and the early XX century. Charles Chedeville in Paris is also known to have made single reed mouthpieces for oboes during the first half of the XX century. All these mouthpieces needed reeds that were much narrower than standard clarinet or saxophone reeds. Nowadays, the company Runyon Products, Inc. in the USA manufactures and sells a single reed mouthpiece for bassoons. This mouthpiece can be used with clarinet reeds.

Some reed woodwind players are of the opinion that the type of reed the instrument is played with is the main factor responsible for the specific sound colour of the instrument they play. Some oboe players, when confronted with the idea of a single reed mouthpiece for an oboe, have commented the following ${ }^{(1)}$ :

"The double reed DEFINES the oboe and sets it aside from other woodwinds, and putting a mouthpiece on it would take away all of its character."

"It would totally take away the oboeness of oboe."

(1) These comments were taken from http://www.8notes.com/f/27_222303.asp 
"The double reed is what makes the unique tone of the oboe, along with the conical bore design."

In this paper we investigate whether the difference in excitation between single and double reed is as dramatic as some reed woodwind players seem to believe. In fact, measurements done recently in double reeds point to the fact that the behaviour of an oboe reed like the one presented in Fig. 1 is not fundamentally different from that of a clarinet reed, as had been thought before. In light of this, it is hypothesised that, given the right parameters, it is indeed possible to build a single reed mouthpiece for an oboe without modifying its characteristic sound or tuning. Some advantages of having such a mouthpiece could be:

1. Oboe playing would be more accessible to other woodwind players such as clarinetists and saxophonists,

2. It would be easier for beginners to learn, since blowing a single reed generally requires less pressure and support,

3. The single reed excitation is less vulnerable, since the mouthpiece forms a natural protection for the reed,

4. The oboist would not have to make his/her own reeds: Buy one from the counter, attach it to the mouthpiece, and play!

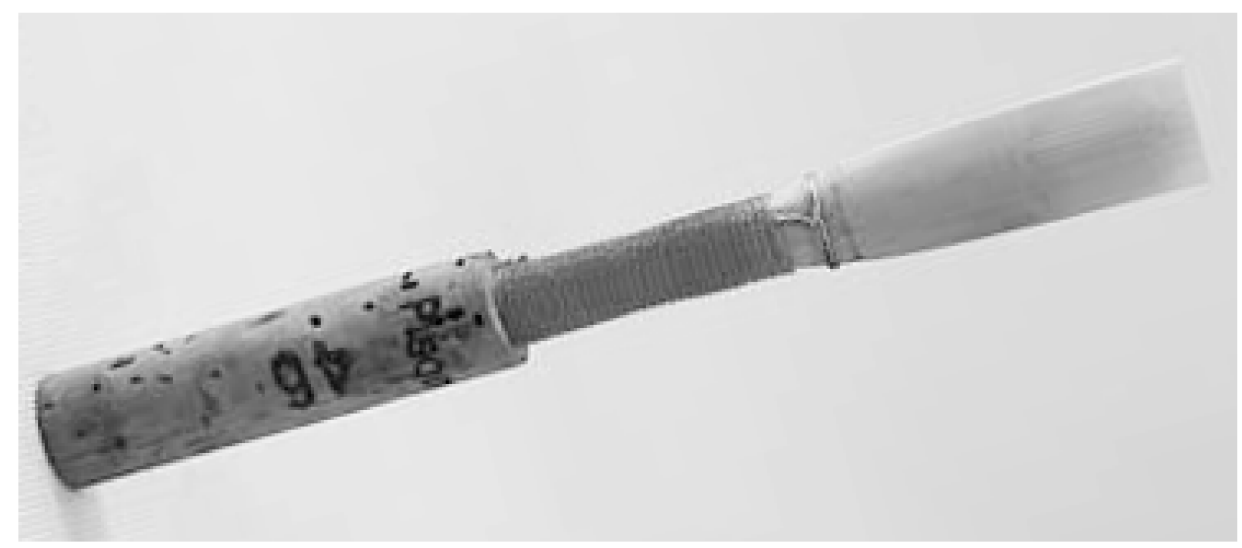

Fig. 1. Typical oboe reed.

This paper is organised as follows: Sec. 2 presents the physics behind the behaviour of single and double reeds, as well as comparative experimental measurements done on them. Section 3 outlines the basic requirements that have to be met in order to successfully build a single reed mouthpiece for an oboe. Section 4 presents the prototype that has been developed according to those requirements, and a comparison of the sound of an oboe played with the prototype vs a standard double reed when played by a professional oboist. In Sec. 5 a short summary and suggestions for future improvement of the prototype, as well as other complementary experiments related to this topic are discussed. 


\section{Double reed functioning}

HiRSCHBERG (1995) presented a model of a double reed with a downstream neck or constriction, like the one shown in Fig. 2. This constriction presents a flow resistance, making the pressure vs flow characteristic curve highly nonlinear and hysteretic. Since then, researchers like (Fletcher, Rossing, 1998) and (VERGEZ et al., 2003) have extrapolated Hirschberg's model to double reeds like those of oboes and bassoons (see (Fletcher, Rossing, 1998), page 405):

"An important modification of this behaviour occurs in the case of double reeds such as those of the oboe and bassoon, in which there is a long narrow passage through the reed. Such a passage can introduce appreciable flow resistance, which can have a significant effect on reed behaviour."

The rest of this Section presents the theory behind the behaviour of the reed excitation mechanism, as well as the results and comparison of experimental measurements between clarinet, oboe and bassoon reeds.

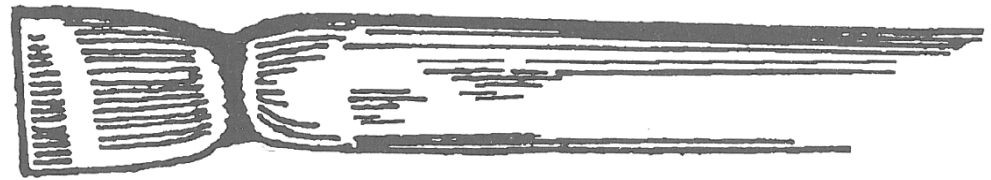

Fig. 2. Sketch of an ancient Egyptian double reed with a neck (taken from (HirschberG, 1995), page 350, with author's permission).

\subsection{Equations}

The relationship between pressure difference across the mouthpiece $\Delta P$ and the volume flow inside the instrument $U$ is described by the Bernoulli equation:

$$
\begin{aligned}
\Delta P & =\frac{1}{2} \rho u^{2}=\frac{1}{2} \rho\left(\frac{U}{S}\right)^{2}, \\
U & =S \sqrt{\frac{2 \Delta P}{\rho}}, \\
S & =w(h+y), \\
y & =\frac{\Delta P}{k},
\end{aligned}
$$

where $u$ is the particle velocity, $S$ is the opening area of the reed (which depends on $\Delta P), U$ is the volume flow, $\rho$ is the density of air, $w$ is the width of the reed, $h$ is the reed opening height at rest, $y$ is the reed displacement, and $k$ is the reed 
stiffness. Equation (4) is represented as the Pressure vs Flow curve in Fig. 3 by the dashed curve.

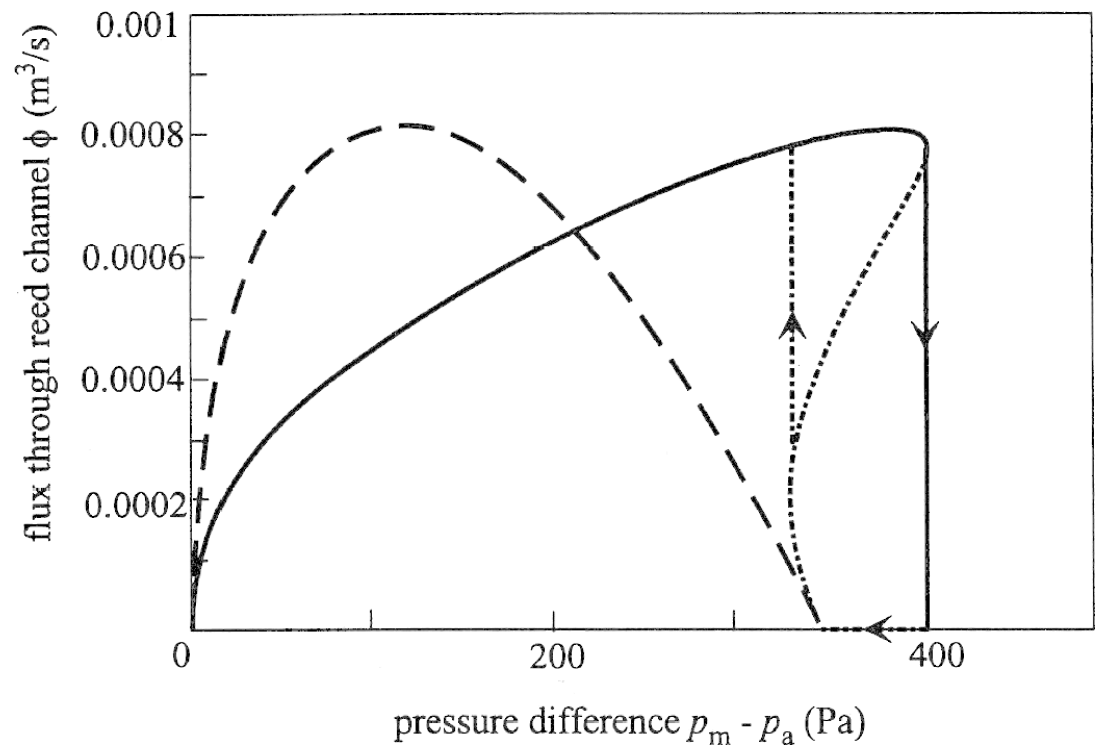

Fig. 3. Pressure vs Flow characteristic curve for a reed with flow separation in the reed channel with (solid) and without (dotted) a downstream neck (taken from (HirschBerG, 1995), page 352, with author's permission).

HiRSCHBERG (1995) presented a model for a double reed with a downstream neck or constriction like the one shown in Fig. 2, which presents a flow resistance, adding an $R U^{2}$ term to the Bernoulli equation, giving:

$$
\begin{gathered}
\Delta P=\frac{\rho}{2}\left(\frac{U}{S}\right)^{2}+R U^{2}, \\
U=S \sqrt{\frac{2 \Delta P}{\rho+2 S^{2} R}} .
\end{gathered}
$$

The curve resulting from Eq. (6) is plotted in Fig. 3 as solid curve. The extra flow resistance shifts the characteristic curve to the right, resulting in a strong hysteretic behaviour.

\subsection{Measurements}

Figure 4 shows the pressure vs flow characteristic measured by ALMEIDA et al. (2007) on oboe and bassoon reeds, as well as the clarinet reed measured by DALMONT et al. (2003). It shows that the characteristic curve of the oboe reed is shifted to the left compared to that of the clarinet reed, and not to the right, as predicted by Hirschberg's model. 


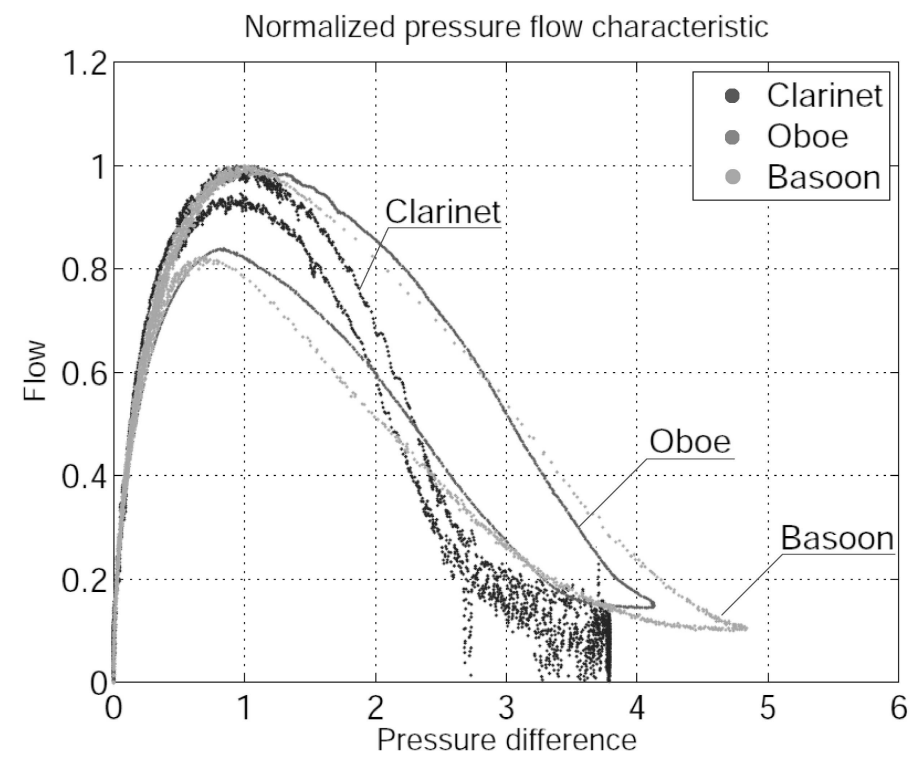

Fig. 4. Comparison between pressure and flow characteristics of clarinet, oboe and bassoon reeds. The measurement corresponding to the clarinet reed was obtained by DALMONT et al. (2003). For the purpose of comparison, all three measurements have been normalised according to the maximum flow and closing pressure (taken from (Almeida, 2006), page 65, with author's permission).

Almeida (2006) presented measurements of the internal profile of an oboe reed (including the staple). They are shown in Fig. 5.

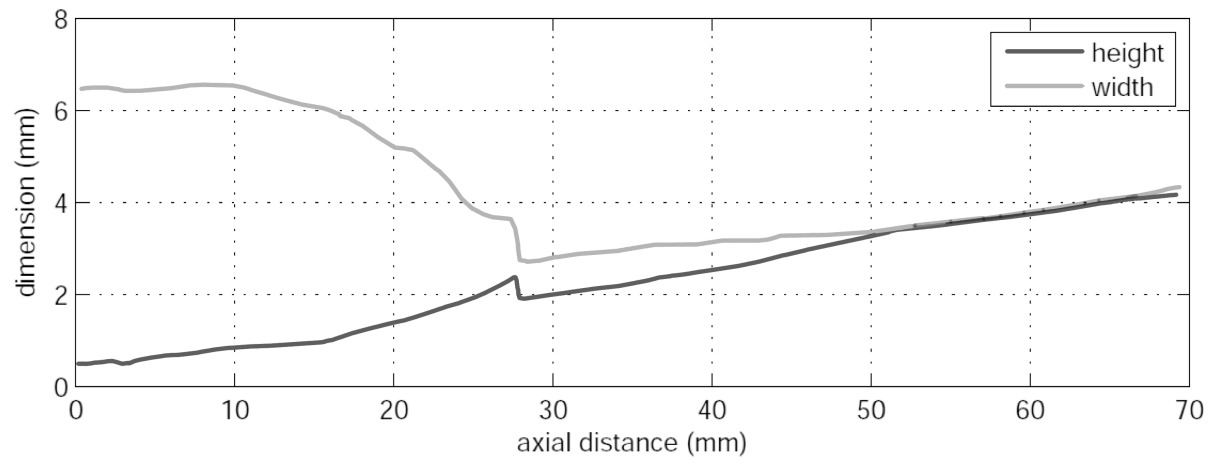

Fig. 5. Internal profile of an oboe reed (taken from (AlmEidA, 2006) page 33, with author's permission).

According to the measurements presented in Fig. 4 it seems that the reed passage is not narrow enough to add a significant extra flow resistance. Furthermore, by comparing the curves of clarinet and oboe in Fig. 4, it can be seen that the behaviour of a double reed is of the same kind as that of a single reed. The only difference lies on the pressure difference at which the flow is maximum: In single 
reeds this is typically at $1 / 3$ of the closing pressure $p_{M}$, by the measurements done by Almeida et al. (2007) it is at $1 / 4$ for oboes and $1 / 5$ for bassoons. He concludes that this effect can be due to the geometry of the staple, which can be assimilated to a conical diffuser.

According to AlmeidA et al. (2007), adding the conical diffuser after the reed results in an extra term:

$$
\Delta P=\frac{\rho}{2}\left(\frac{U}{S}\right)^{2}-\alpha U^{2}
$$

where

$$
\alpha=\frac{\rho}{2} \frac{C_{P}}{S_{i n}^{2}},
$$

$C_{P} \approx 0.8$ is the pressure recovery coefficient, and $S_{i n}$ is the opening area at the top of the conical diffuser. It follows then that the volume flow is:

$$
U=S \sqrt{\frac{2 \Delta P}{\rho-2 S^{2} \alpha}} .
$$

\section{Mouthpiece requirements}

In order to have a mouthpiece with the same behaviour of a double reed, the following considerations have been made:

- Mouthpiece Volume: According to (Nederveen, 1998), in order for at least the first two modes to be tuned properly, a cavity volume must be added to the top of the instrument that is approximately equal to the volume of the missing part of the cone $\left(V_{c}\right)$. In practice, it seems that a cavity volume somehow larger than $V_{c}$ results in better tuning in the upper register (see (NEDERVEEN, 1998) page 39, Figure 27.4). Deviations from the preferred value of this volume strongly influence the intonation in the high register and the upper part of the low register (NEDERVEEN, 1998).

The staple was considered to be a continuation of the instrument itself, therefore for the mouthpiece prototype, $V_{c}$ will be defined as the missing part of the cone taken from the top end of the staple (the end where the two reed blades would be attached) until the cone apex. An approximation of $V_{c}$ can be obtained from real oboes, or from oboe bore schematics such as the one shown in Fig. 6. Measurements of $V_{c}$ vary greatly between oboes, presumably because each oboe is made differently. Measurements of $V_{c}$ done in Fig. 6, on a similar schematic taken from (CAMPBELL et al., 2004) page 77, and on an oboe owned by one of the authors (SC) reveal the following values: $0.248,0.119$ and $0.134 \mathrm{~cm}^{3}$, respectively.

The cavity volume must include the volume induced by the reed motion $V_{r}$ so that:

$$
V_{c}=V_{m}+V_{r},
$$




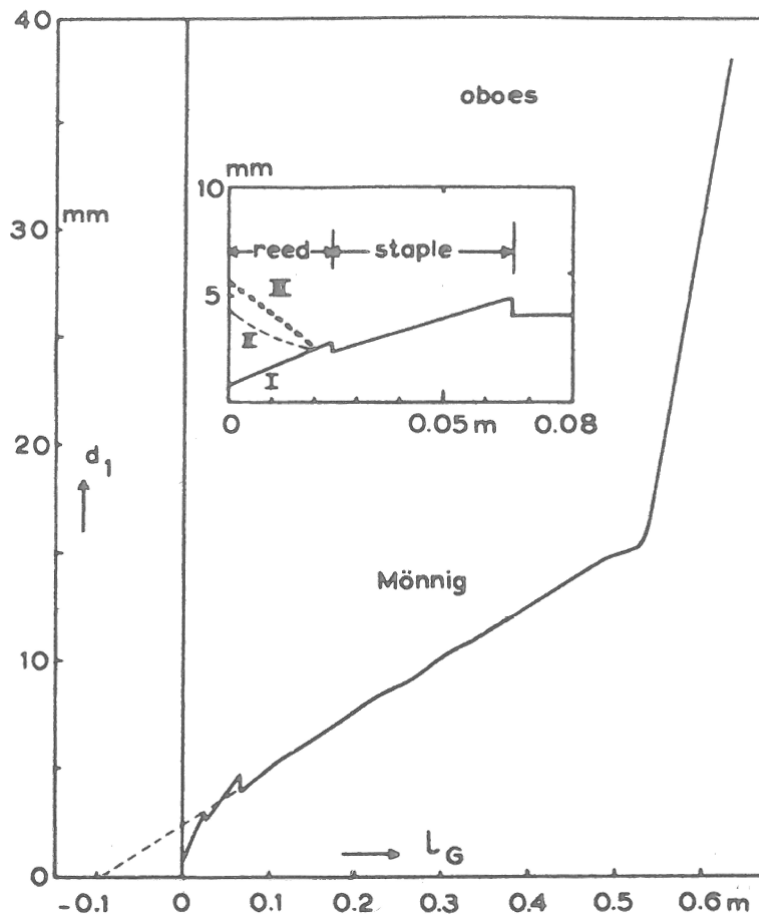

Fig. 6. Internal bore profile of an oboe (taken from NeDERVEen, 1998, page 88, with author's permission).

where $V_{m}$ is the volume inside the mouthpiece. The volume induced by the reed motion on a double reed can be calculated as follows (NEDERVEEN, 1998, page 41, equation 27.13$)$ :

$$
V_{r}=\frac{2}{3} K \int B C \mathrm{~d} x
$$

where $K$ is the bulk modulus $\left(1.4 \times 10^{5} \mathrm{~N} / \mathrm{m}^{2}\right), B$ is the reed width (approximately $7 \mathrm{~mm}$ for oboe reeds), and $C$ is the reed compliance. An estimate of the integral of Eq. (11) can be obtained from NederveEn (1998, Figure 25.6, page 31): $2 \times 10^{-10} \mathrm{~m}^{4} / \mathrm{N}$, giving $V_{r} \approx 0.13 \mathrm{~cm}^{3}$.

From Eq. (11) it follows that

$$
V_{m}=V_{c}-V_{r} .
$$

From the three $V_{c}$ measurements shown before, $V_{m}$ can be calculated to be $0.118,-0.011$ and $0.004 \mathrm{~cm}^{3}$. In practice, $V_{m}$ on a double reed would be the volume in between the blades of the two reeds. This volume can be calculated with careful measurements in Fig. 5, from Fig. 6, or by carefully measuring the volume inside a reed, giving $V_{m}$ values of $0.16,0.061$, and $0.1 \mathrm{~cm}^{3}$ respectively.

It is worth noting that all these figures are only rough approximations, and should only serve as a guideline. Different bore, staple and reed geometries will 
lead to very different values. In practice, the required mouthpiece volume will have to be found by a process of trial and error.

The mouthpiece volume used for this prototype was approximately $0.12 \mathrm{~cm}^{3}$.

- Mouthpiece Total Length: Given the fact that the proposed mouthpiece will have a very different geometry than that of a double reed, it is possible that a different length will be required in order to achieve the desired pitch. However, making the total length of the mouthpiece plus staple of approximately the same length of a standard double reed seems to be, from both acoustical and ergonomic perspectives, a good starting point.

A quick survey on reeds and reed makers (see Table 2) revealed that the assumed standard total length of the oboe reed is $72 \mathrm{~mm}$, and that of the staple is $47 \mathrm{~mm}$. This is if the player wishes to play at $A_{4}=440 \mathrm{~Hz}$. Reeds get shorter, down to $69 \mathrm{~mm}$ (usually on shorter staples as well), for people who wish to play at a higher $\operatorname{pitch}^{(2)}$.

Table 2. Length of reed plus staple and of staple alone by different oboe reed makers.

\begin{tabular}{|l|c|c|}
\hline Reed maker & $\begin{array}{c}\text { Staple length } \\
{[\mathrm{mm}]}\end{array}$ & $\begin{array}{c}\text { Total reed length } \\
{[\mathrm{mm}]}\end{array}$ \\
\hline www.britanniareeds.com & $45-47$ & $69-72.5$ \\
\hline www.girardreeds.com & 47 & 72 \\
\hline www.chaseoboereeds.co.uk & 47 & 72 \\
\hline www.reedmaker.co.uk & $45-47$ & $70-72$ \\
\hline
\end{tabular}

- Mouthpiece Staple: The mouthpiece should allow the insertion of a standard oboe reed staple, since it is hypothesised (Almeida et al., 2007) that it is the staple's geometry that is responsible for the difference in behaviour between single reeds and double reeds.

- Mouthpiece Width: The intention is to use a standard clarinet $B^{b}$ reed that can be bought in any music store and used immediately. The maximum width at the top of a traditional Vandoren reed is $13 \mathrm{~mm}$.

- Mouthpiece tip shape: The tip of the mouthpiece should match the shape of a standard clarinet reed.

- Mouthpiece tip thickness: The thickness at the top of the mouthpiece should be as thin as possible, so that an oboe player can still use his/her accustomed embouchure.

- Distance between reed and mouthpiece lay: It has been found by trial and error that a distance of $0.8 \mathrm{~mm}$ between mouthpiece lay and reed presents a good compromise between a loud and full tone and ease of play.

- Other geometrical considerations: Sharp edges inside the mouthpiece should be avoided, in order to avoid turbulence and noise that would result from it.

\footnotetext{
${ }^{(2)}$ It is worth noting that the surveyed companies shown in Table 2 are all in Europe. The length of reeds made in the USA may vary considerably from these measurements.
} 


\section{Mouthpiece Prototype}

A prototype based on the above requirements was built, as shown in Fig. 7 . In order to find out if the sound of the oboe played with this mouthpiece is comparable to that of the oboe played with a standard double reed, a recording was made with both mouthpieces, and the sounds resulting from it were compared. This experiment is described below.

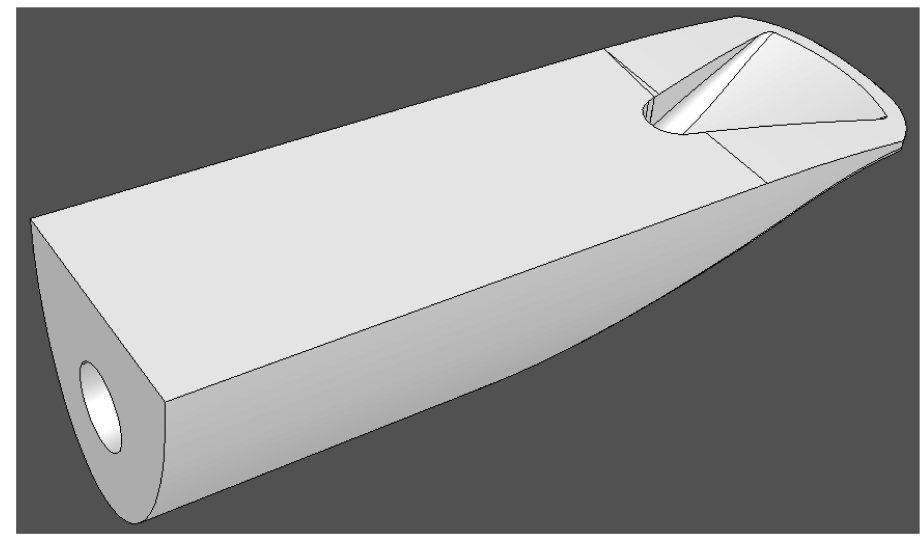

Fig. 7. Mouthpiece prototype.

\subsection{Sound comparison between the prototype and a standard double reed}

A professional oboe player was asked to play a melody of her choice five times with a standard double reed and five times with the single reed mouthpiece and a standard Vandoren reed strength 5. The player was asked to play her oboe for a few minutes with the mouthpiece prototype, so as to familiarise herself with it. She did not have any previous experience with it before. The melody she played is "Blues for oboe" written by Christopher Norton, and is shown in Fig. 8. The recording was done in an anechoic chamber. A free field $1 / 4^{\prime \prime}$ ROGA instruments microphone type RG-50 was placed close to her left ear, so that the recorded sounds corresponded approximately to what the player would hear. The microphone was then connected to a PCB sensor signal conditioner model 442B104. The output of the signal conditioner was connected to a Phantom MPA
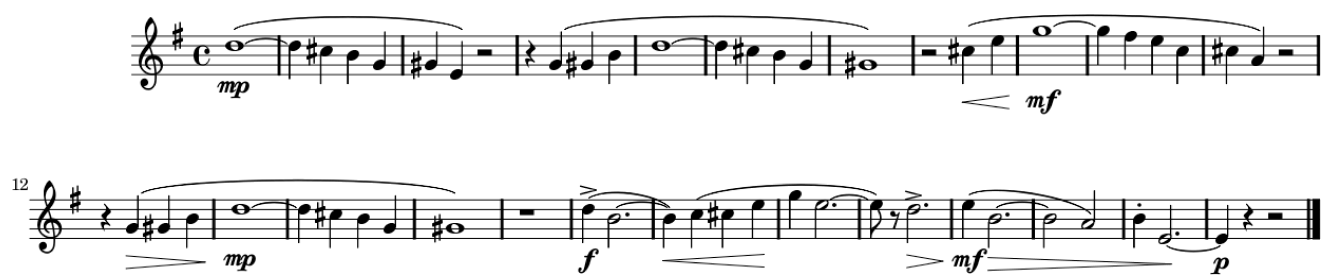

Fig. 8. Melody played by a professional oboe player on the mouthpiece prototype and a standard double reed of her choice. 
2017 preamplifier. The level of the signals from the preamplifier was adjusted to be as high as possible without saturating. This adjustment was made once, at the beginning of the measurement. The output from the preamplifier was then connected to an ADAT HD24 digital recorder, which converted the signals from analog to digital, and into an optical interface, before being connected to an RME computer sound card model DIGI96/8 PST. The sounds were recorded with the aid of the program Sony Sound Forge v 7.0. The sampling frequency was set at $44.1 \mathrm{kHz}$.

After having played her own oboe with the two mouthpieces (the prototype shown in Fig. 7 and a standard double reed of her choosing), her opinion was that the instrument with the single reed mouthpiece sounds as if it were being played with a standard plastic double reed. She also commented on the intonation being flat.

\subsubsection{Analysis of recorded sounds}

Each played instance was saved separately in a mono .wav file. All instances were analysed with the aid of the program SNDAN (BEAUCHAMP, 1993; 2007), which performs frequency tracking analysis based on the McAulay and Quatiery method (McAulay, QuATIERI, 1986). The minimum frequency

$$
f_{\min }=\frac{1}{T_{\max }}
$$

must be specified, which corresponds to the lowest expected fundamental frequency. The window size $\left(2^{N}\right.$ samples, where $N$ is a positive integer) is chosen so that

$$
2^{N}>3 T_{\max } f s .
$$

The selected window is multiplied by a Kaiser window (to improve peak separation), and then it is zero-padded until its size is doubled (to improve frequency resolution). An FFT is calculated. The FFT magnitude peaks are searched. The amplitude $A_{k}$ and frequency $f_{k}$ of the $k$-th peak are found by parabolic interpolation, taking the three points found of each peak on the FFT. Those peaks whose amplitude $A_{k}$ is bigger than a threshold specified by the user are saved in an analysis file. Subsequent windows are overlapped by a hop size of $1 / 4$ of the window size (before zero padding).

The analysis delivers an analysis file with information about the amplitudes $A_{k}[n]$ and frequencies $f_{k}[n]$ of the $k$ peaks that are present at every time frame $n$. The time between frames $t_{n}-t_{n-1}$ depends on the minimum frequency $f_{\min }$ and on the sampling frequency $f_{s}$, and is found from Eq. (14):

$$
t_{n}-t_{n-1}=\frac{2^{N} / 4}{f_{s}}
$$

$f_{\min }$ will be determined by the lowest note of the melody that was played. 
In this case, since the lowest note played was an E4 (nominal playing frequency of this note is approximately $330 \mathrm{~Hz}), f_{\min }$ was chosen to be $300 \mathrm{~Hz}$. With a sampling frequency $f_{s}=44100 \mathrm{~Hz}$, and $f_{\min }=300 \mathrm{~Hz}$, from Eq. (14) the sample size results in $2^{9}=512$. Similarly, from Eq. (15) the time between frames results in approximately $3 \mathrm{~ms}$.

\subsubsection{Calculation of comparison parameters}

From each analysis file (corresponding to each of the samples of the two instrument groups), the parameters RMS, fundamental frequency and normalised spectral centroid can be calculated as follows (BEAUCHAMP, 1993; 2007):

- RMS amplitude:

$$
R M S[n]=20 \cdot \log _{10}\left(\sqrt{\sum_{k=1}^{K} A_{k}^{2}[n]}\right)[\mathrm{dB}] ;
$$

- Fundamental frequency:

$$
\mathcal{P}[n]=1200 \cdot \log _{2}\left(\frac{F[n]}{F_{\text {ref }}}\right)[\text { cents }]
$$

where

$$
F[n]=\frac{\sum_{k=1}^{5} \frac{A_{k}[n] \cdot f_{k}[n]}{k}}{\sum_{k=1}^{5} A_{k}[n]}[\mathrm{Hz}]
$$

and $F_{\text {ref }}$ is the frequency in $\mathrm{Hz}$ of the tonic $\mathrm{E} 4(329.6 \mathrm{~Hz}$ in the case of the melody shown in Fig. 8.

- Normalised spectral centroid:

$$
N S C[n]=\frac{\sum_{k=1}^{K} k \cdot A_{k}[n]}{\sum_{k=1}^{K} A_{k}[n]}[\text { dimensionless]. }
$$

For each of these parameters, the average and standard deviation over the five instances played for each mouthpiece are calculated.

\subsubsection{Results}

The average and standard deviation of the parameters RMS, playing frequency and normalised spectral centroid are shown in Figs. 9-11, respectively. 


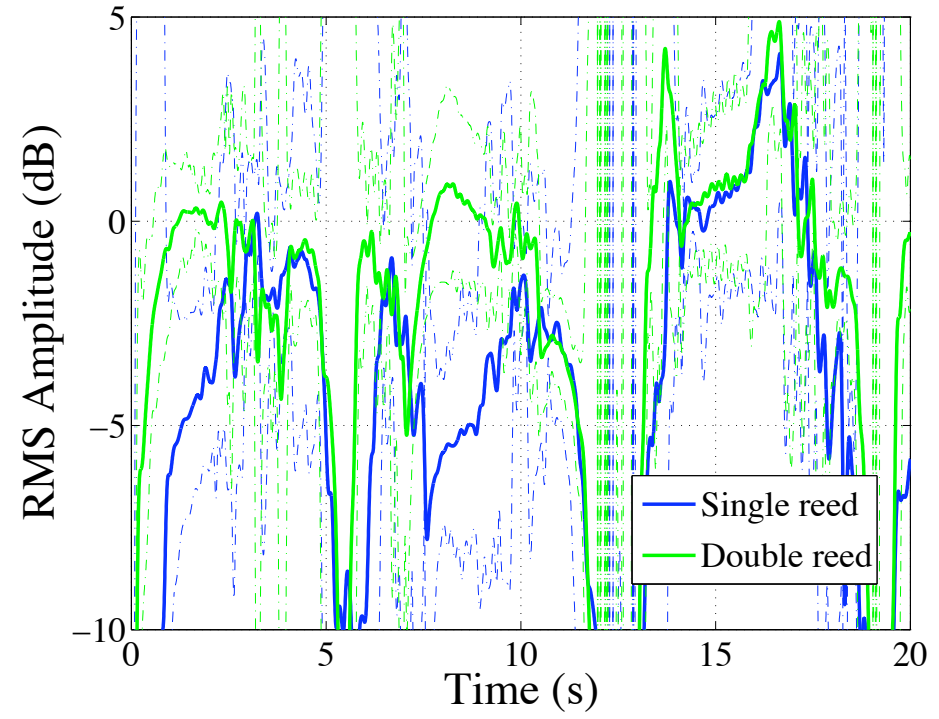

Fig. 9. RMS vs time averaged over the five played instances. The solid line represents the average over the five played instances, and the dashed lines \pm standard deviation.

Figure 9 shows that the oboe played with the double reed was 3 to 5 dB louder than with the single reed, except for the highest note, where there does not seem to be a difference. Close inspection of Fig. 10 reveals that the playing frequency of the oboe was approximately 50 cents lower when played with the single reed

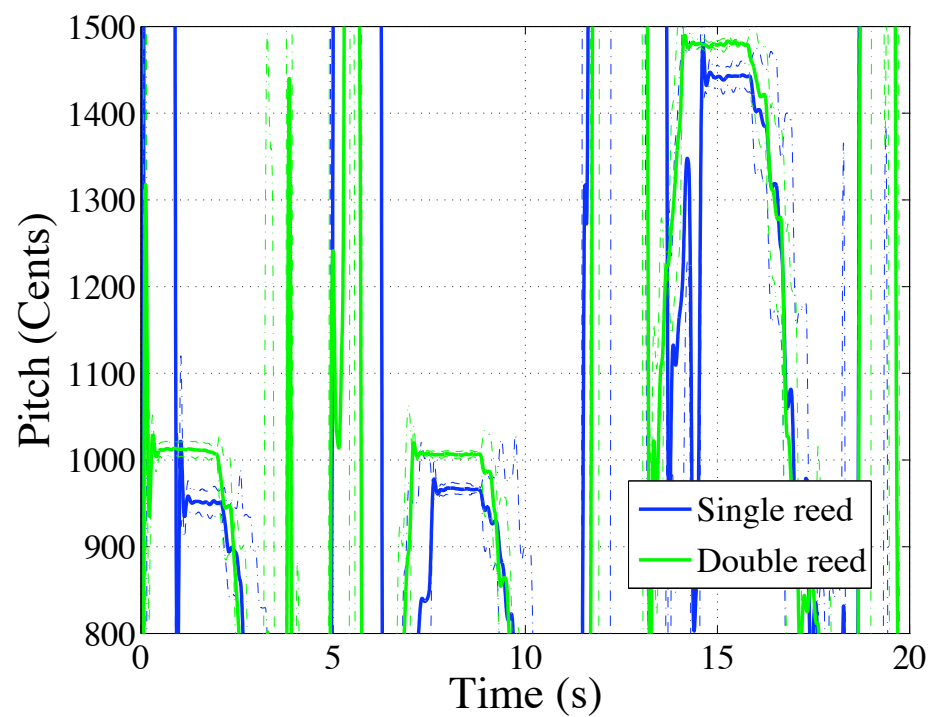

Fig. 10. Playing frequency vs time averaged over the five played instances. 0 cents corresponds to the nominal frequency of note E4 $(329.63 \mathrm{~Hz})$. The solid line represent the average over the five played instances, and the dashed lines \pm standard deviation. 
mouthpiece than with the standard double reed. This is an indication that the volume inside the mouthpiece is too large. Figure 11 shows that the normalised spectral centroid of the oboe played with the single reed mouthpiece is in most notes higher than with the standard double reed. The only exception was the highest note played, which was a G5, where the situation was reversed.

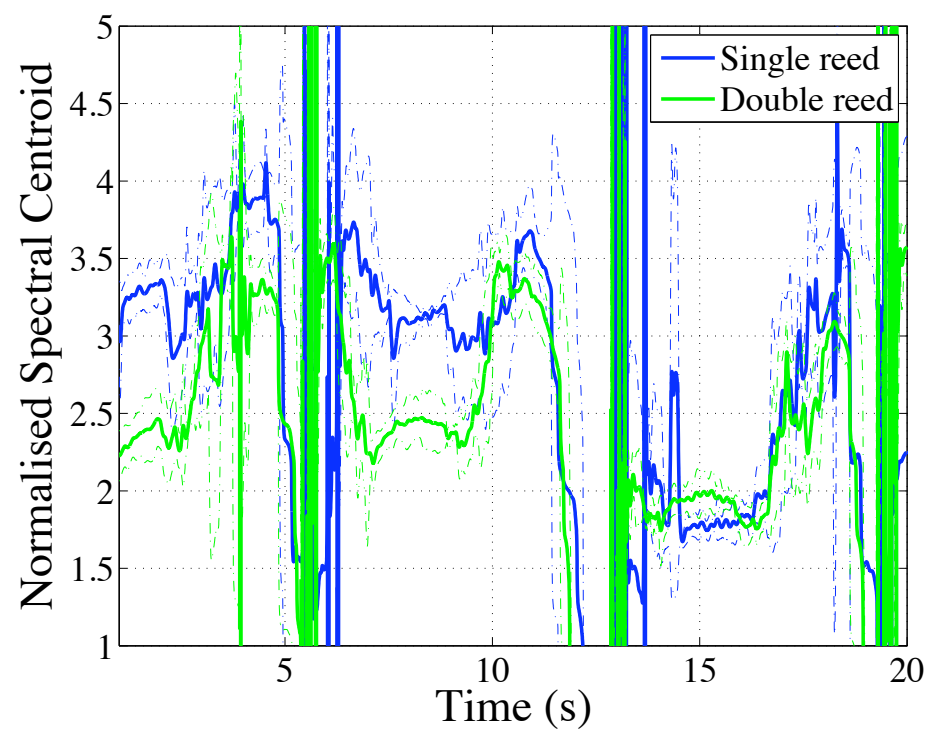

Fig. 11. Normalised spectral centroid (dimensionless quantity) vs time. The solid line represent the average over the five played instances, and the dashed lines \pm standard deviation.

\section{Conclusions and future work}

In the attempt to find out whether the excitation mechanism of reed woodwind instruments differs by the type of reed used (i.e. single vs double reed), resulting in a difference in sound, a prototype of a single reed mouthpiece for an oboe was developed. The prototype shown in Fig. 7 is already playable. Initial recordings of the sound of an oboe played by a professional oboist using a clarinet reed attached to this prototype and a standard double reed were done, and analysed using the program SNDAN. Comparison between the analysed recordings shows that the sound of the oboe played with the presented prototype is about 3 to $5 \mathrm{~dB}$ softer, 50 cents flat, and that the timbre seems brighter than that of the double reed. These differences are not to be ignored, especially the fact that the intonation was so much lower. Some essential modifications that are planned to try to improve sound and intonation include:

- reducing the volume inside the mouthpiece,

- modifying the shape of the mouthpiece cavity to match the cross section area profile of an oboe reed. 
Once these modifications are done and a new prototype is developed, sound tests such as the one described in Subsec. 4.1 will be performed, whereby several musicians will be invited to play. Furthermore, a measurement of the pressure vs flow characteristic curve is also planned, in order to confirm experimentally Almeida's hypothesis.

A second prototype has already been developed with a slightly lower cavity volume. The intonation has been largely improved compared to the prototype presented here. Results of a sound test and the characteristic curve measurement will be presented in a future article.

In the same line of work, a cylindrical woodwind instrument that can be played with both single and double reed is currently being developed, as well as a double reed mouthpiece for a tárogató.

\section{Acknowledgments}

We would like to present our deepest gratitude to Stefan Devic (SERM, LMA) for his hard work helping us do the 3D prototyping of the single reed mouthpiece.

\section{References}

1. Almeida A. (2006), The physics of double-reed wind instruments and its application to sound synthesis, Ph.D Thesis, Université Paris VI.

2. Almeida A., Vergez C., Caussé R. (2007), Quasistatic nonlinear characteristics of double-reed instruments, Journal of the Acoustical Society of America, 121, 1, 536-546.

3. Beauchamp J.W. (1993), Unix workstation software for analysis, graphics, modification, and synthesis of musical sounds, Audio Engineering Society, page Preprint 3479.

4. Beauchamp J.W. (2007), Analysis and synthesis of musical instrument sounds, [in:] Analysis, synthesis and perception of musical sounds: The sound of music, BEAUCHAMP J.W. [Ed.], Springer, 1-89.

5. Campbell M., Greated C., Myers A. (2004), Musical Instruments - History, Technology, and Performance of Instruments of Western Music, Oxford University Press.

6. Carral S., Vergez C., Nederveen C.J. (2010), The characteristic sound of the oboe: Can it be played with a single reed and still maintain its tone colour?, [in:] Proceedings of Vienna Talk 2010, pp. 35-38, Vienna, Austria, University of Music and performing Arts, Vienna.

7. Dalmont J.-P., Gilbert J., Ollivier S. (2003), Nonlinear characteristics of singlereed instruments: Quasistatic volume flow and reed opening measurements, Journal of the Acoustical Society of America, 114, 4, 2253-2262.

8. Fletcher N.H., Rossing T.D. (1998), The physics of musical instruments, Springer, second edition.

9. Hirschberg A. (1995), Aero-acoustics of wind instruments, [in:] Mechanics of musical instruments, Hirschberg A., Kergomard J., Weinreich G. [Eds.], pp. 291-369, Springer-Verlag. 
10. McAulay R.J., Quatieri T.F. (1986), Speech analysis/synthesis based on a sinusoidal representation, IEEE Transactions on Acoustics, Speech, and Signal Processing, ASSP-34, $4,744-754$.

11. Nederveen C.J. (1998), Acoustical aspects of woodwind instruments, Northern Illinois University Press.

12. Vergez C., Almeida A., Caussé R., Rodet X. (2003), Toward a simple physical model of double-reed musical intruments: Infuence of aero-dynamical losses in the embouchure on the coupling between the reed and the bore of the resonator, Acta Acustica united with Acustica, 89, 964-973. 